\title{
Electronic Cigarette Solvents, JUUL E-liquids, and Biomarkers of Exposure: In Vivo Evidence for Acrolein and Glycidol in E-cig-derived Aerosols
}

\author{
Pawel Lorkiewicz $z^{a, b, c, d}$, Rachel Keitha,b,c,e Jordan Lynch,c, Lexiao Jin ${ }^{\mathrm{a}, \mathrm{b}}$, Whitney Theis ${ }^{\mathrm{a}, \mathrm{b}}$, \\ Tatiana Krivokhizhina ${ }^{\mathrm{a}, \mathrm{b}, \mathrm{c}}$, Daniel Riggs ${ }^{\mathrm{b}, \mathrm{c}, \mathrm{e}}$, Aruni Bhatnagara,b,c,e, Sanjay Srivastava ${ }^{\mathrm{a}, \mathrm{b}, \mathrm{c}, \mathrm{e}}$ \\ and Daniel J. Conklin ${ }^{a, b, c, e *}$
}

\begin{abstract}
${ }^{a}$ American Heart Association-Tobacco Regulation and Addiction Center, University of Louisville, Louisville, KY 40202, USA;

${ }^{b}$ Christina Lee Brown Envirome Institute, University of Louisville, Louisville, KY 40202, USA;

'Superfund Research Center, University of Louisville, Louisville, KY 40202, USA;

dDepartment of Chemistry, University of Louisville, Louisville, KY 40202, USA; and, eDivision of Environmental Medicine, Department of Medicine, University of Louisville, Louisville, KY 40202, USA
\end{abstract}

\section{Supporting Information File}

\section{$\underline{\text { Table of Contents }}$}

\begin{tabular}{ll} 
Page & Contents \\
\hline S1 & Title Page
\end{tabular}

S2 Figure S1 caption describing images of electronic cigalike platform used to generate PG:VG- and JUUL e-liquid-derived aerosols

S3 Figure S2 caption describing urinary excretion kinetics of acrolein metabolite in PG:VGand JUUL e-liquid-derived aerosol-exposed mice

S4 Figure S3 caption describing urinary excretion kinetics of metabolites of acetaldehyde (acetate) and formaldehyde (formate) in JUUL e-liquid-derived aerosol-exposed mice 
A.

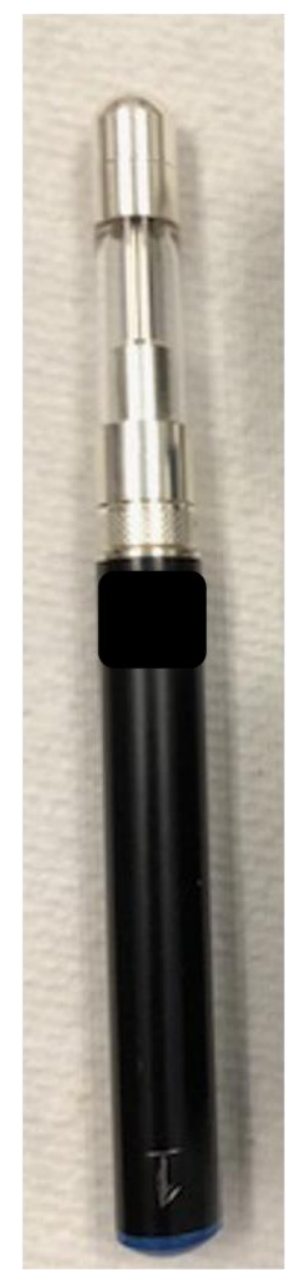

B.

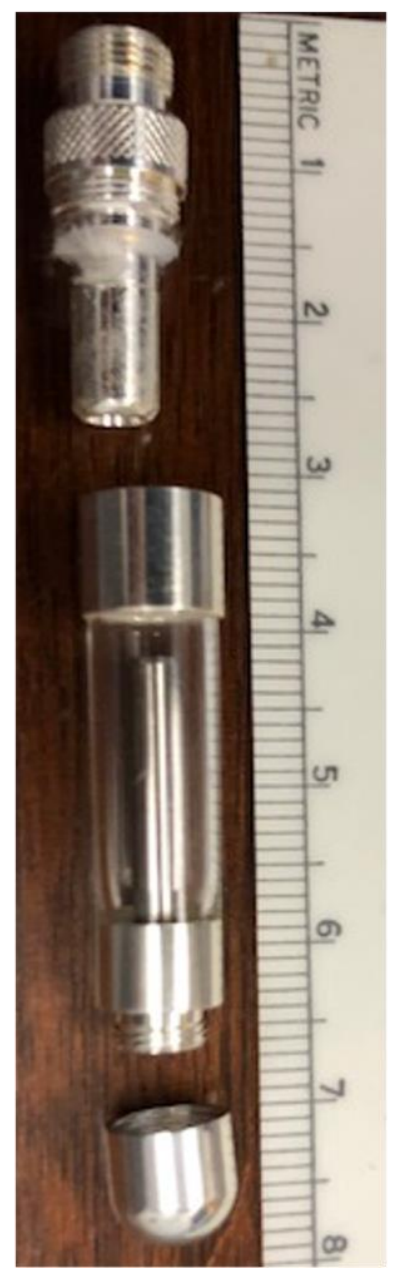

C.

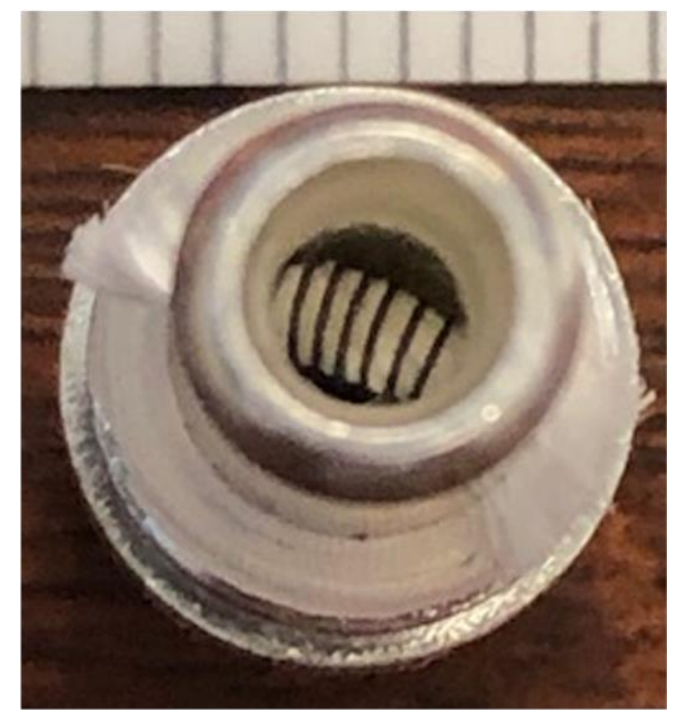

Figure S1: Images of electronic cigalike platform used to generate PG:VG- and JUUL-derived aerosols in controlled exposures. A) A Mistic Bridge coupled with bluPlus battery (3.7 V) to create a uniform vaping platform ${ }^{1}$. B) Disassembled Mistic Bridge clear tank cartomizer (0.5 mL). C) Top-down view of Mistic Bridge coil (2.4 Ohms) and wick. Overall, Mistic-bluPlus e-cig wattage was $5.7 \mathrm{~W}$ (V * $(\mathrm{V} / \mathrm{R})=3.7 \mathrm{~V} *(3.7 \mathrm{~V} / 2.4 \Omega)=5.7 \mathrm{~W})$ and was similar to the JUUL platform $\left(8.1 \mathrm{~W}=3.7 \mathrm{~V}\right.$ * $(3.7 \mathrm{~V} / 1.6 \Omega)^{2}$. 


\section{HPMA}

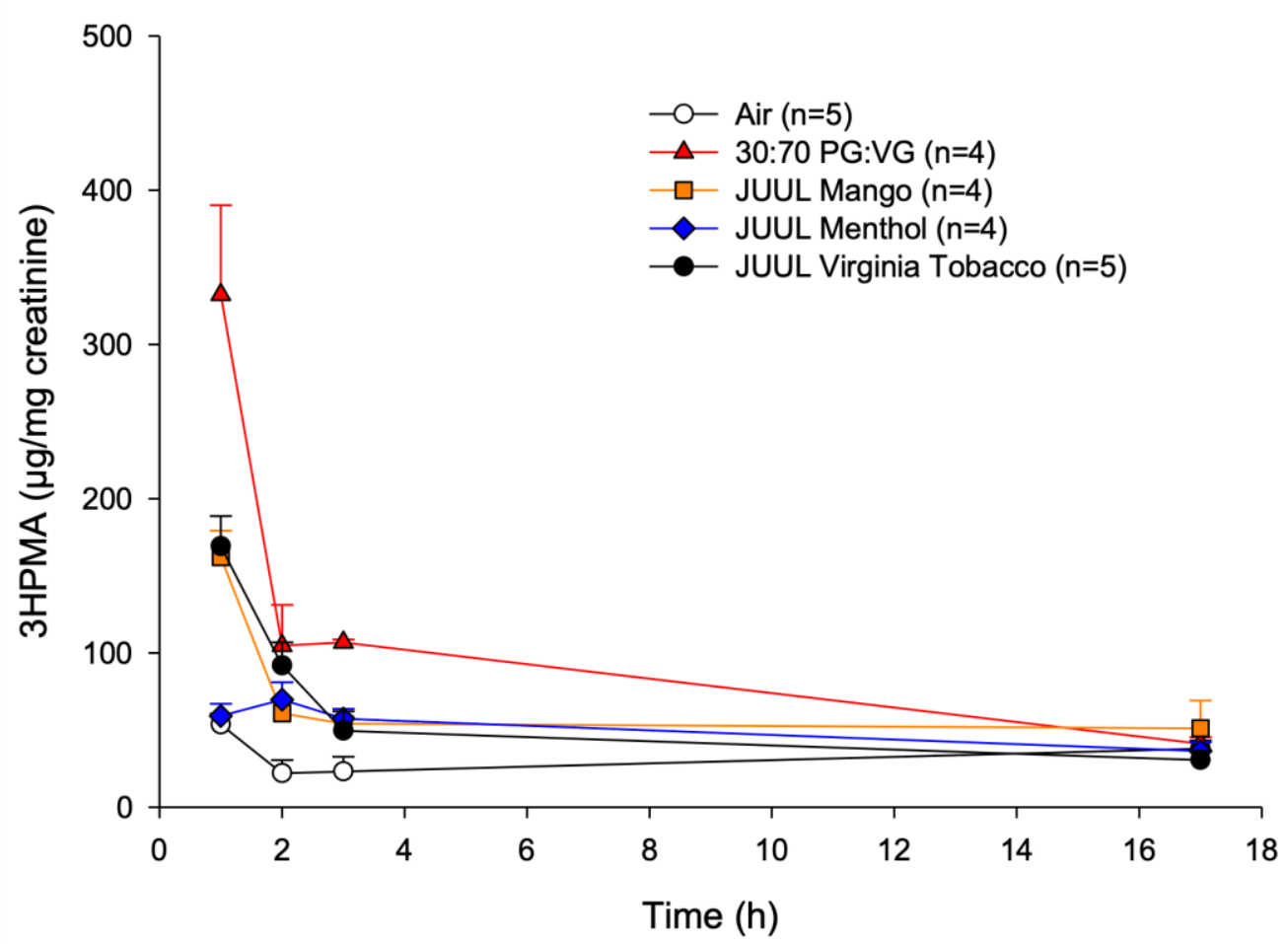

Figure S2: Excretion kinetics of acrolein metabolite in in PG:VG- and JUUL e-liquid-derived aerosol-exposed mice. Urinary concentration of 3-hydroxypropylmercapturic acid (3HPMA) at $0-3 \mathrm{~h}$ and 3-17h after a $6 \mathrm{~h}$ exposure of male C57BL6J mice to filtered air or PG:VG- (30:70 v:v) or JUUL eliquid-derived aerosols. Values $=$ mean \pm SEM ( $n=4-5$ male mice per group); * $p<0.05$ vs air control. 


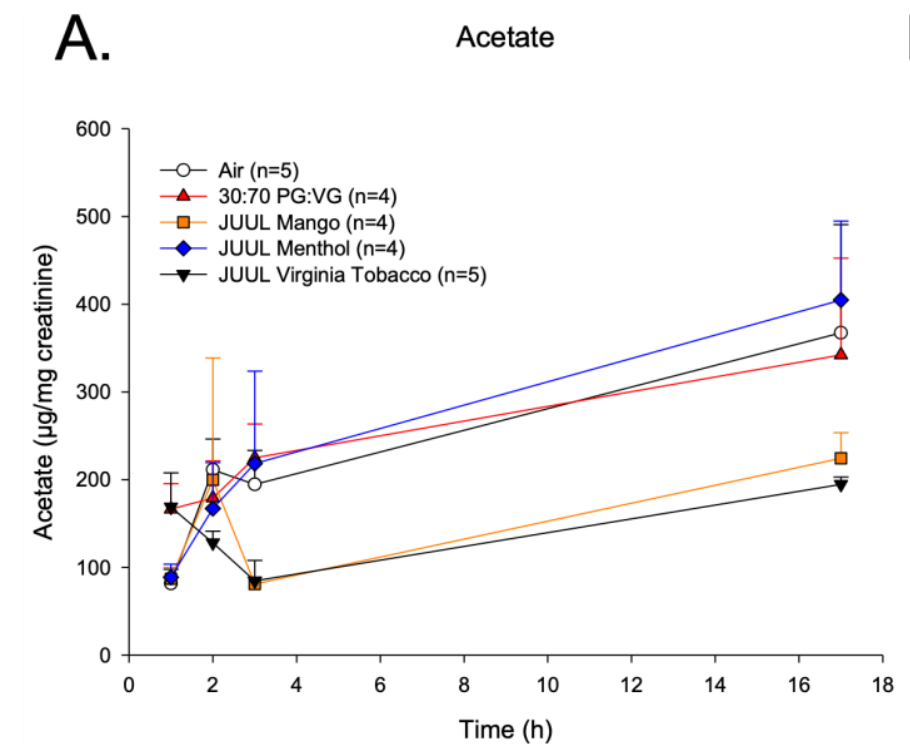

B. Formate

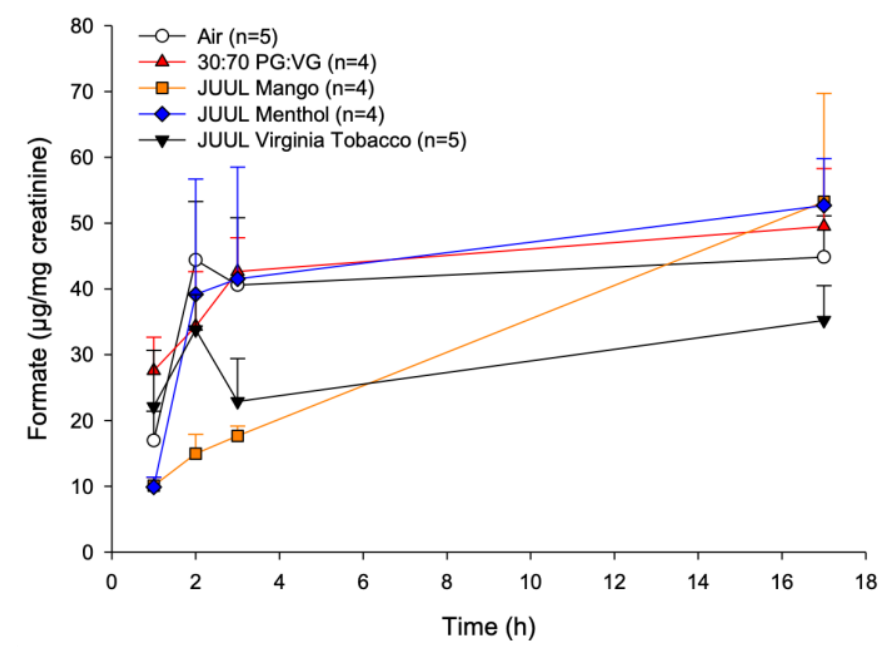

Figure S3: Excretion kinetics of metabolites of acetaldehyde (acetate) and formaldehyde (formate) in urine of JUUL e-liquid-derived aerosol-exposed mice. Urinary levels of A) acetate and B) formate at 1, 2, 3 and 3-17h after a $6 \mathrm{~h}$ exposure of male C57BL6J mice to filtered air, PG:VG- or JUUL e-liquid-derived aerosols. Values $=$ mean \pm SEM ( $n=4-5$ male mice per group); ${ }^{*}, p<0.05$ vs air control. 


\section{References}

(1) Conklin, D. J., Ogunwale, M. A., Chen, Y., Theis, W. S., Nantz, M. H., Fu, X. A., Chen, L. C., Riggs, D. W., Lorkiewicz, P., Bhatnagar, A., and Srivastava, S. (2018) Electronic cigarettegenerated aldehydes: The contribution of e-liquid components to their formation and the use of urinary aldehyde metabolites as biomarkers of exposure. Aerosol Sci Technol, 52, 1219-1232.

(2) Talih, S., Salman, R., El-Hage, R., Karam, E., Karaoghlanian, N., El-Hellani, A., Saliba, N., and Shihadeh, A. (2019) Characteristics and toxicant emissions of JUUL electronic cigarettes. Tob Control, 28, 678-680. 